\title{
Controversial Issues in Deep Brain Stimulation in Parkinson's Disease
}

\author{
Shin-Yuan Chen ${ }^{1,2}$, Sheng-Tzung Tsai ${ }^{2}$ and Sheng-Huang Lin ${ }^{3}$ \\ ${ }^{1}$ Division of Functional Neuroscience, \\ ${ }^{2}$ Department of Neurosurgery \\ ${ }^{3}$ Neurology, Neuro-Medical Scientific Center \\ Tzu Chi General Hospital / Tzu Chi University, Hualien \\ Taiwan
}

\section{Introduction}

Since 1992, the application of subthalamic nucleus deep brain stimulation (STN-DBS) for Parkinson's disease (PD) has been shown to induce dramatic and stable long-term improvement of patients' motor symptoms. However, some of the motor symptoms, and most of the non-motor symptoms, may not be improved by STN-DBS; in fact, they may deteriorate after surgery. Even after the successful introduction of STN-DBS as a treatment for PD, controversy still exists over a variety of issues: patient selection criteria, the anatomical target such as STN or globus pallidus (GPi), targeting methods (MRI alone, CT scan with image fusion, or ventriculography), microelectrode recordings (yes/no), and anesthetic procedures (awake with sedative or under general anesthesia). In this chapter we will discuss these controversial issues by integrating our experience with a review of the literature.

\section{Patient selection for deep brain stimulation (DBS)}

A successful DBS surgery may involve several surgical procedures, but patient selection is always a key issue to address because it contributes to whether there is a good surgical outcome. In 1992, a common evaluation protocol for PD was suggested by the the Core Assessment Program for Intracerebral Transplantations(CAPIT) committee, which allowed for comparisons between different study groups. For example, they defined "offmedication" and "on-medication" status. The core assessment methodologies of this protocol include the following: Unified Parkinson's Disease Rating Scale (UPDRS), Hoehn and Yahr Staging, Dyskinesia Rating Scale, Self-reporting diary, and timed test for bradykinesia [1]. In 1996, the Network for European CNS Transplantation and Restoration (NECTAR), developed a new Core Assessment Program for Surgical Interventional Therapies in PD (CAPSIT-PD) and gave advice to add evaluations for cognitive function and quality of life [2]. Since then, thousands of papers have been published in the fields of PD and DBS, and clinicians and researchers have paid attention to the issue of patient selection in order to ensure a good outcome [3-9]. 
In 2009, Australia offered a referral guideline for neurologists to establish methods for enrolling ideal PD candidates for DBS. In 2010, consensus was reached for DBS in PD. With respect to patient selection, these experts stated that, “...Best results have been reported in patients with advanced PD and (1) levodopa response, (2) younger age, (3) no or few axial non-LD-responsive motor symptoms, (4) no or very mild cognitive impairment, and (5) absence of or well controlled psychiatric disease" [10]. The ideal candidate has all of the above components; however, even with these guidelines, pitfalls and controversy still exist.

\section{Diagnosis}

It is important to differentiate PD from atypical parkinsonism to ensure a good long-term outcome of STN-DBS, but it can be hard to discriminate between them because they share clinical features such as bradykinesia, rigidity and tremor. It is especially difficult when the disease is in its early stage and l-dopa responsiveness is moderate. Poor prognostic factors for STN-DBS can be the following: a poor response to l-dopa, the additional presence of pyramidal or cerebellar signs (e.g., ataxia), an early presentation of posture instability and autonomic failure (e.g., hypotension), within 5 years of onset, a nontremor dominant presentation, and persistent unilateral disease [11-12]. The UK Brain Bank Diagnostic Criteria for PD is recommended for assessing all surgical candidates, although it should be noted that the early symptoms of PD, such as hyposmia, REM sleep behavioral disorders, constipation and depression may precede the obvious motor symptoms and are not included on the list [13]. The use of Hoehn and Yahr (H\&Y) staging and the Unified Parkinson's Disease Rating Scale (UPDRS) is a basic requirement for evaluating patients before starting any PD intervention. In 2007, the revising process for the UPDRS was started by a task force of the Movement Disorder Society (MDS), which is aimed at incorporating more detail on non-motor symptoms, but it has not yet been published [14-17].

\section{Age at time of surgery}

Age is a confounding factor and has a negative correlation with STN-DBS outcome. A trend for greater long-term STN-DBS improvements on the UPDRS part II and part III measures in younger patients has been shown; however, it is also effective in elderly patients, though the benefits may persist for only a short period of time [18]. Most studies also have shown a negative correlation with motor outcome, non-motor outcome (e.g., apathy and depression) and quality of life upon long-term follow-up [18-22]. While the cut-off age proposed by most studies is 70 years old, the benefits and risks of surgery should be weighed to meet the expectations of the patient and the care giver.

\section{Disease duration and severity}

Advanced PD patients with obvious medication side effects of motor fluctuation and/or dyskinesia would be good candidates for DBS. However, an H\&Y Stage 1 patient with tremor dominant symptoms who is within 5 years of onset can also be a good candidate for DBS and show a substantial benefit, as can a bed-ridden Stage 5 patient. Because there have been no proven neuroprotective effects of DBS, the recommendation for an earlier intervention is based on quality of life, which will improve substantially in domains related to movement disorders and general health [23]. Though some authors postulate that disease severity may be correlated with STN-DBS outcome, a study of ours found that the outcome was not correlated with H\&Y staging or disease duration [18]. 


\section{Levodopa (LD) responsiveness}

LD responsiveness, as measured by the UPDRS part III, may predict the motor outcome of STN-DBS in a PD patient with disabling motor fluctuations and dyskinesia. In fact, this is true for all cardinal symptoms (except LD refractory tremor) that can be well controlled by STN-DBS. Pre-operative LD responsiveness may only lead to consistent UPDRS part III improvement from STN-DBS at 3 months, and its predictive value may not be valid for long-term follow-up due to co-morbid non-motor symptoms. The pre-operative LD responsiveness of tremor and axial symptoms are stable predictors for the long-term effect of DBS [18].

\section{Cognitive, psychiatric, and other non-motor symptoms}

Non-motor symptoms in PD patients are a significant source of disability and impairment in the performance of activities of daily living. The non-motor symptoms of PD include dementia, sleep disorders, and dysautonomia along with neuropsychiatric and sensory complaints. Most centers exclude PD patients with dementia and neuropsychiatric symptoms from STN-DBS. As for sleep disorders and sensory complaints, some reports have shown improvement after treatment when these symptoms are present. More generally, normal pre-operative cognitive functioning is positively correlated with postoperative improvement in UPDRS part III at a long-term follow-up [18]. STN-DBS may still lead to a decline in cognitive and executive function even with strict inclusion criteria [24]; however, it has been suggested that sub-optimal contact stimulation (caused by the small volume of STN) is more strongly correlated with post-operative psychiatric events. Although there are still debates about post-operative psychiatric events, the possibility of increased depression and suicide risk prompts us to evaluate the patient's psychological function in detail prior to the operation.

\section{STN-DBS versus GPi-DBS: Which target is better for PD patients?}

STN-DBS is the current gold-standard surgical treatment in PD, but a high occurrence of adverse effects and neuropsychological problems following STN-DBS stimulation cause some centers to study alternative surgical targets, such as the GPi. The issues to consider when choosing a target for DBS include the following: a different set of patient selection criteria, the amount of levodopa being used, the extent of levodopa-related dyskinesia, battery life and surgeon preference.

In randomized trials, DBS has been demonstrated to be superior to the best knownmedical treatment for advanced PD. Under most circumstances, STN is the chosen target rather than GPi. Although several reports have shown that the efficacy of pallidal stimulation decreases over the long-term follow up [25], others have demonstrated a persistent benefit from pallidal stimulation for up to 3 years [26]. In 2005, the first randomized trial was published by Anderson and colleagues, and their patients showed a similar improvement in motor function from subthalamic and pallidal stimulation [27]. Still, deciding which target is best is a topic still subject to debate, and several points of view need to be considered.

\section{The effect of target on motor function}

PD is characterized by disabling motor symptoms. Previous reports seem to have concluded that STN-DBS improves more than GPi-DBS in UPDRS part III (motor) [26-28]. However, a 
recent large randomized trial showed a similar improvement from either STN or GPi stimulation [29]. It should be noted that the follow-up duration in this study was only 24 months and GPi might show less of a benefit after a longer period of time $[25,30]$.

\section{The effect of target on non-motor symptoms}

Non-motor symptoms of PD have received more attention in recent years and seem to play a pivotal role in the change in quality of life caused by the amelioration of motor disabilities through medical or surgical treatment [31]. An increased percentage of post-stimulation behavioral and cognitive complications is still a major concern for STN-DBS [27, 32-33] as it is not conclusively known whether DBS causes a change in these non-motor symptoms. Although a recent randomized trial comparing PD patients undergoing STN stimulation to those who only received the best medication-based treatment showed no significant differences [34], a second study comparing STN stimulation with GPi did show that depression was worse in those who received STN-DBS [29]. This finding reminds us that non-motor symptoms should be considered during target selection for patients who plan to receive electrode implantation.

\section{The effect of target on reducing medication dosages}

One of the main reasons that pallidal stimulation has not become popular may be that it limits the amount one can decrease medication dosages. Most studies have shown that patients who undergo STN stimulation require a lower dose of dopaminergic medication than those who undergo GPi stimulation [28-29]. This effect is probably due to different mechanisms of action underlying the STN and GPi response to electrical current. It has been suggested that STN stimulation reverses the sensitization phenomenon that underpins levodopa induced dyskinesia (LID) [35]. In fact, STN stimulation per se cannot ameliorate LID without decreasing dopaminergic medication[36]. Contrary to this, GPi stimulation may itself decrease the severity of LID [37]. The interaction between STN and GPi activity has been suggested to play a major role in the pathogenesis of dyskinesia, and the amelioration of stimulation-related dyskinesia through proximal contact (i.e., stimulating pallido-subthalamic fibers) shown in previous reports and our own young onset PD (YOPD) patients suggests a more beneficial effect of GPi than STN in ameliorating treatment-related dyskinesia. Overall, most comparative studies showed that the daily dosage of levodopa can be reduced only in an STN-DBS group [26].

\section{The effect of target on battery life}

The stimulation amplitude within the implantable pulse generator (IPG) is one significant determinant of battery life. In a multicenter study, Rodriguez-Oroz and colleagues found a similar amplitude for patients undergoing STN and GPi stimulation for 3 to 4 years [26]. However, most studies (including one large randomized trial) have shown that STN stimulation requires significantly less electrical power around $0.7 \sim 0.8 \mathrm{~V}$ and a pulse width of $20 \mu \mathrm{sec}$ [38]. These parameters allow patients to receive STN stimulation for a longer period of time between pulse-generator replacements as compared to GPi stimulation. Most cost-effectiveness studies also have confirmed this benefit of STN stimulation over solely medication-based treatment for advanced PD. For countries where DBS devices are not reimbursed by health insurance, such as Taiwan, the replacement of the IPG will be a large burden for most patients. Larger amplitudes and pulse widths for GPi stimulation may lead to more frequent battery replacement and more device-related complications [30]. Improving future IPG technology may alleviate this economic consideration. 


\section{Adverse effects of target}

Adverse effects of stimulation in general include cognitive decline, verbal fluency deterioration, gait disorders and mood instability (in the form of compulsiveness or depression). Most studies show that the adverse effects of stimulation are more common in STN-DBS [27, 29]. In the COMPARE trial, which was a prospective randomized trial, it was shown that under optimal conditions there was no significant difference in the incidence of mood or cognitive alteration following DBS implantation. However, a sub-scale analysis of the Visual Analogue Mood Scale showed that there was more "anger" after STN-DBS. Another randomized trial also has suggested that depression may be worse after subthalamic stimulation but improved after pallidal stimulation.

The volume of the STN ( $\left.158 \mathrm{~mm}^{3}\right)$ is much smaller than the GPi $\left(\sim 478 \mathrm{~mm}^{3}\right)$ nucleus. Moreover, the sub-territory within the STN nucleus and surrounding fibers involve motor, associative and limbic circuitry that are more compact and close together. Therefore, a suboptimal electrode placement or electrical-current perturbation is more often going to be associated with STN stimulation, which may lead to mood changes and verbal fluency dysfunction.

Although a randomized control trial has shown a comparable benefit for GPi stimulation compared to STN stimulation, longer follow-up studies are needed to decide which target is preferable for each patient. We have made a comparison of the targets in Table 1. Clinical trials are ongoing for alternative targets in the pedunculopontine nucleus, radiation prelemniscalis, and caudal zona incerta, and stimulation on these targets may improve symptoms that are currently unresponsive to treatment with either levodopa or STN stimulation.

\begin{tabular}{lll}
\hline & STN stimulation & GPi stimulation \\
\hline Motor improvement & $50 \sim 60 \%$, coherent $[29,34]$ & 27 50\%, variable in long-term [29, 72] \\
Mood effect & $\begin{array}{l}\text { higher, esp. suboptimal } \\
\text { contact }\end{array}$ & seems unchanged \\
LEDD reduction & greater reduction $(31.5 \%)$ & less reduction $(17.8 \%)$ \\
Battery life & lower amplitude & higher amplitude \\
General adverse effect & $56 \%$ & $51 \%$ \\
\hline
\end{tabular}

Table 1. Comparison of STN and GPi stimulation

\section{Targeting methods in DBS: MRI alone versus CT scan fused with MRI and/or ventriculography}

There are a number of targeting methods used in DBS. Which method is used depends on the facilities of the institution and the familiarity of the surgeon with a given procedure. Most practicing centers use magnetic resonance imaging (MRI) as the only tool for targeting, but others use image fusion techniques to co-register MRI and computed tomography (CT) images, or intra-operative ventriculography, which is the traditional targeting method, for determining targeting accuracy. Below we compare these methods on acquisition time, procedure complexity, and ultimate accuracy. 
The size of the STN is extremely small and it has an ovoid shape and oblique orientation [39]. The accuracy of DBS targeting may be one of the most important factor in surgical outcome because the position of the electrode determines the area across which the electrical current diffuses. Given that there are very few evidence-based studies that have directly compared the safety and effectiveness of the various imaging techniques, the best targeting method remains under debate. The methods include MRI, CT, ventriculography and various combinations thereof.

Stereotactic targeting with ventriculography is the traditional method for stereotactic functional neurosurgery that has been in use for decades. While it is still used by some teams, there are concerns over its invasiveness and serious complications, such as CSF leakage and intracranial hemorrhage, which are major obstacles for most functional neurosurgeons [40]. The method involves injecting a contrast medium into the right frontal horn and acquiring representative images to determine the location of the anterior commissure and posterior commissure, which then can be used to calculate various target coordinates [41]. Compared with targeting methods that may have higher accuracy (e.g., ventriculography), targeting with MRI can be affected by the anterior displacement of the anterior commissure (AC), which elongates anterior commissure - posterior commissure (AC-PC) length [40]. A magnetic field can cause this nonlinear distortion, especially in the anterior-posterior and medial-lateral axis.

Most centers only use MRI for targeting while others use image fusion techniques to coregister MRI and CT scans. MRI-directed targeting for STN-DBS has proven to be a simple yet accurate method in most DBS practicing centers; it has been a standard procedure in our hospital since 2002 [42]. The advantages of MRI includes better demarcation of deep nuclei (e.g., the red and subthalamic nucleus) as references for targeting, better visualization of critical structures that can prevent inadvertent injury (e.g., lateral ventricles and vasculatures within sulci) and a clear delineation of simulating trajectory for electrode.

There are three current strategies to localize the coordinates of targets on stereotactic MRI. In direct targeting, the STN is located on MRI without any references, which is inherently prone to errors. The vague configuration of the STN makes determining the STN boundaries on a T2-weighted MR image rely on the subjective visual impression of the neurosurgeon. An indirect method of targeting uses the AC and PC as reference points, thereby avoiding bias when differentiating the border between the STN and substantia nigra, which has been shown to be more accurate than direct targeting. Targeting based on the red nucleus (RN) has not only the same accuracy as indirect targeting but also less variance, which indicates greater precision across subjects (Fig. 1) [43]. Although MRI-based targeting is becoming more popular, the potential distortion of the STN that a nonlinear magnetic field can induce is still a major concern. To counter this, some groups still use ventriculography which reliably identifies the AC-PC for indirect targeting methods using intraventricular landmarks.

Although the AC-PC and the target itself (e.g., the STN) are poorly visualized on CT, MRI fused to stereotactic CT are believed to combine the advantages of both modalities, thereby increasing the spatial validity of the image and ensuring a more accurate localization, which continues to improve as fusion technology improves [44]. In our experience, stereotactic CT fused to MRI during DBS surgery can allow for a longer microelectrode recording length of STN and fewer recording tracts (Fig. 2). This indirectly demonstrates that stereotactic CT may have a better pre-operative targeting ability leading to the stimulation of optimal anatomical sites. It should be noted that it may be difficult for advanced PD patients to 


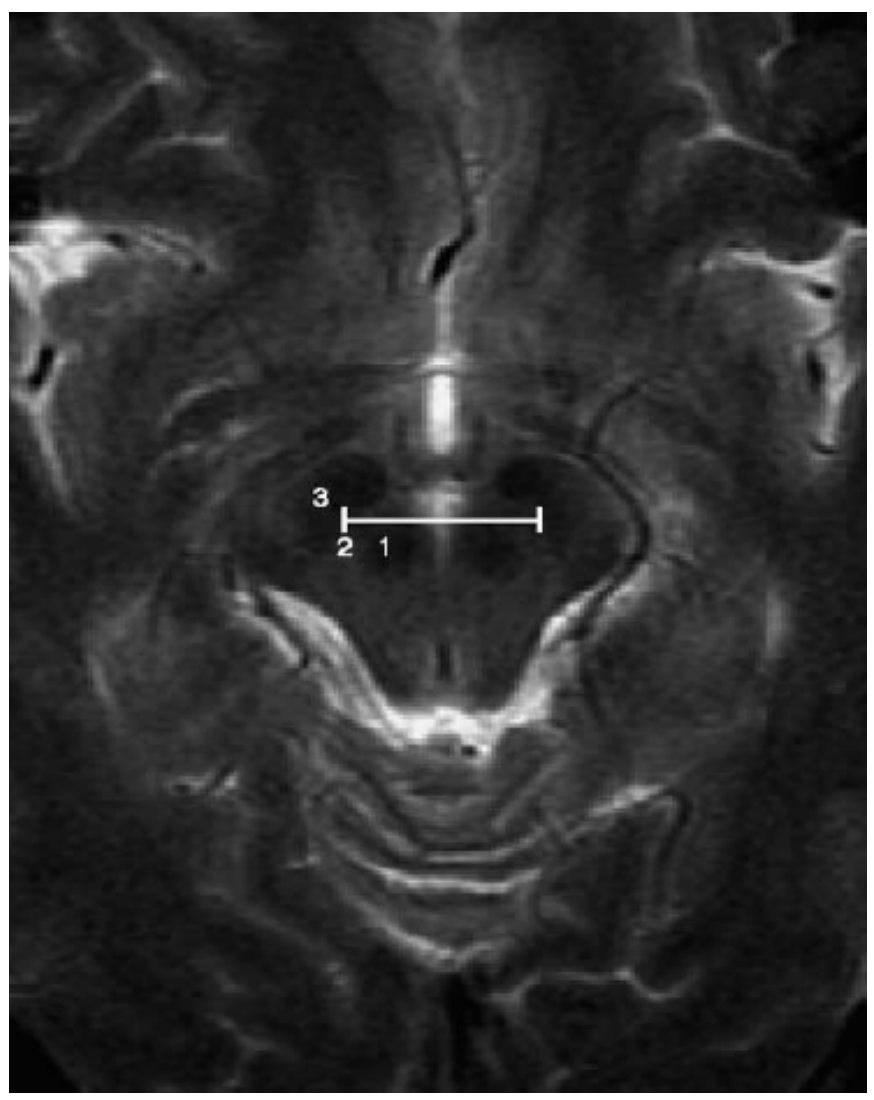

Fig. 1. Direct targeting using MR images is depicted. The target coordinates for the tip of the permanent implantable electrode are at the intersection of the perpendicular lines. The horizontal line is located along the anterior border of the red nucleus. The longitudinal lines are at 2-mm intervals from the lateral border of the red nucleus. Axial section taken at the level of the superior colliculus, just below the lowest border of the STN ( $4.5 \mathrm{~mm}$ below the mid-commissural point). 1 = red nucleus; $2=$ substantia nigra reticulata; $3=$ crus cerebri.

undergo MRI with a stereotactic frame, especially in an un-medicated state where obvious tremors or severe stoop posture will be present. There is a risk for these patients when sedated in the MRI suite in an attempt to quell the severe tremor because the scanning time for MRI may take more than 20 minutes. For this reason, some centers use a specific protocol for direct visualization of the STN in stereotactic MRI, which saves time [45]. At our institution, a stereotactic CT scan takes about 3 minutes, which is far below the average MRI acquisition time of 20-25 minutes for most protocols.

With advances in imaging technology, we may be able to define the border of the STN directly using MRI in the future and eliminate the inherent error of nonlinear MRI distortion. 


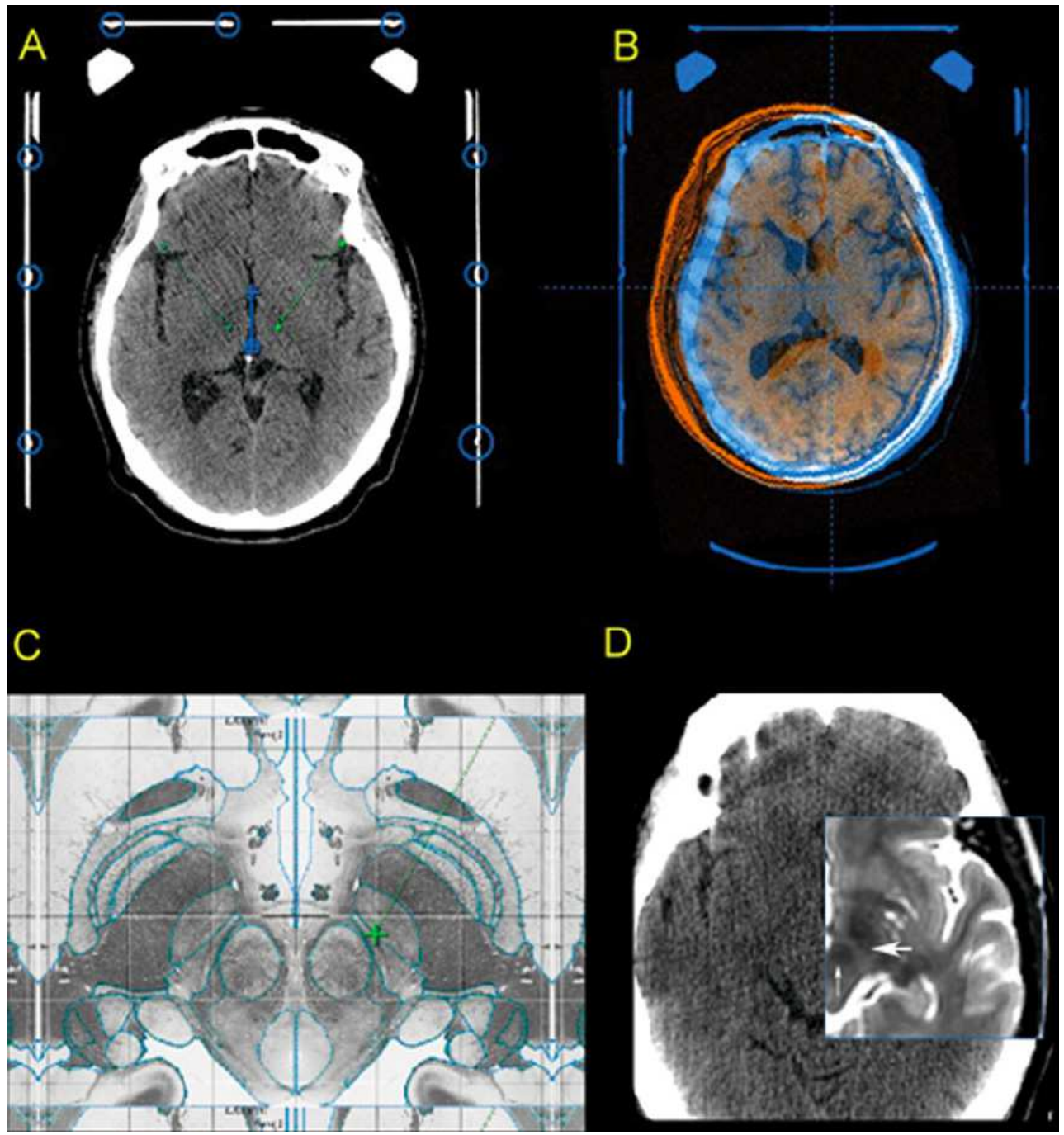

Fig. 2. (A) Stereotactic axial computed tomography (CT) images for fiducial registration. (B) Nonfused axial magnetic resonance image (MRI) T1 images and stereotactic CT images. (C) Co-registered Schaltenbran-Wahren atlas for red nucleus and subthalamic nucleus (STN) target planning simulation. (D) Fused axial MRI T2 and CT images, spyglass with visualization of red nucleus (thin arrow) and STN (thick arrow). 


\section{The necessity of microelectrode recording in STN-DBS surgery}

Precise results in DBS surgery are traditionally achieved by MRI targeting followed by electrophysiological confirmation with microelectrode recording (MER) [46]. MRI scans are not always of sufficient quality to identify the target structure and are always susceptible to image distortion. MER can localize the target with more precision when MRI targeting is not precise enough. MER is used in DBS surgery to identify the target's structural border, the subdivisions of the targeted structure and the outlines of its three-dimensional shape. MRI and MER are complementary in DBS surgery [47]; however, there are disadvantages of MER in DBS surgery, including the following: 1) it is time consuming, 2) it may increase the risk of a hemorrhage complication and 3) it is not always useful, for example when the target is located in white matter or has a large and distinct boundary that can be easily visualized with MRI. Here we will focus on whether MER is necessary in STN-DBS surgery for treating PD.

Direct MRI targeting without MER is possible in STN-DBS surgery with the recent advances in high-resolution MRI (field strength of 3-Tesla or more) and advanced image processing techniques. However, there is a paucity of publications that report on the use of stereotactic MRI for direct visualization in STN-DBS surgery without MER [48]. Recently, a large series of STN-DBS without MER has been published by Foltynie et al. [49]. We compared their results with those of Krack et al [50], who performed STN-DBS with MER which recruited from a single center. Table 2 compares the demographic data of the studies' patients, effect of DBS and complications of surgery. The baseline data of the patients are comparable except that Krack's sample size is less than Foltynie's. However, we should note that Krack's report is designed for long term follow-up (5 years later) and they recruited the first 49 STNDBS patients from their center. The effect of STN-DBS at a one-year follow-up was similar in the two studies. The DBS effect is better in Krack's study but not significantly so. In terms of surgery-related adverse events, Krack showed greater transient confusion and intracerebral hemorrhage in their patients. Foltynie showed less transient confusion and no hemorrhage events.

The risk of intracerebral hemorrhage inevitably increases with a greater number of micro- or DBS electrode penetration events [51-52]. Post-operative transient confusion in DBS surgery is common. The incidence of transient confusion in STN-DBS surgery is $15.6 \%$ [53]. This phenomenon is often attributed to a mild pneumocephalus that occurs during surgery. It is not a precisely understood phenomenon, but it occurs more frequently in older and cognitively disabled patients. The risk for and volume of pneumocephalus positively correlates with the amount of time the skull is open during surgery. MER may therefore increase the risk of pneumocephalus because it is time consuming.

Based on the above comparison, the same therapeutic effect for patients can be achieved in STN-DBS with and without MER, but MER has more surgery-related adverse events. Others have reported that the use of MER improves the outcome of STN-DBS [42]. With the advancement of MRI technology and imaging processing, MRI-guided STN-DBS without MER may be an alternative surgical method for advanced PD patients. The reports of MRIguided STN-DBS are sparse; therefore, we cannot conclude that this surgical method is better than STN-DBS with MER. Overall, the necessity of MER in STN-DBS surgery remains controversial. 


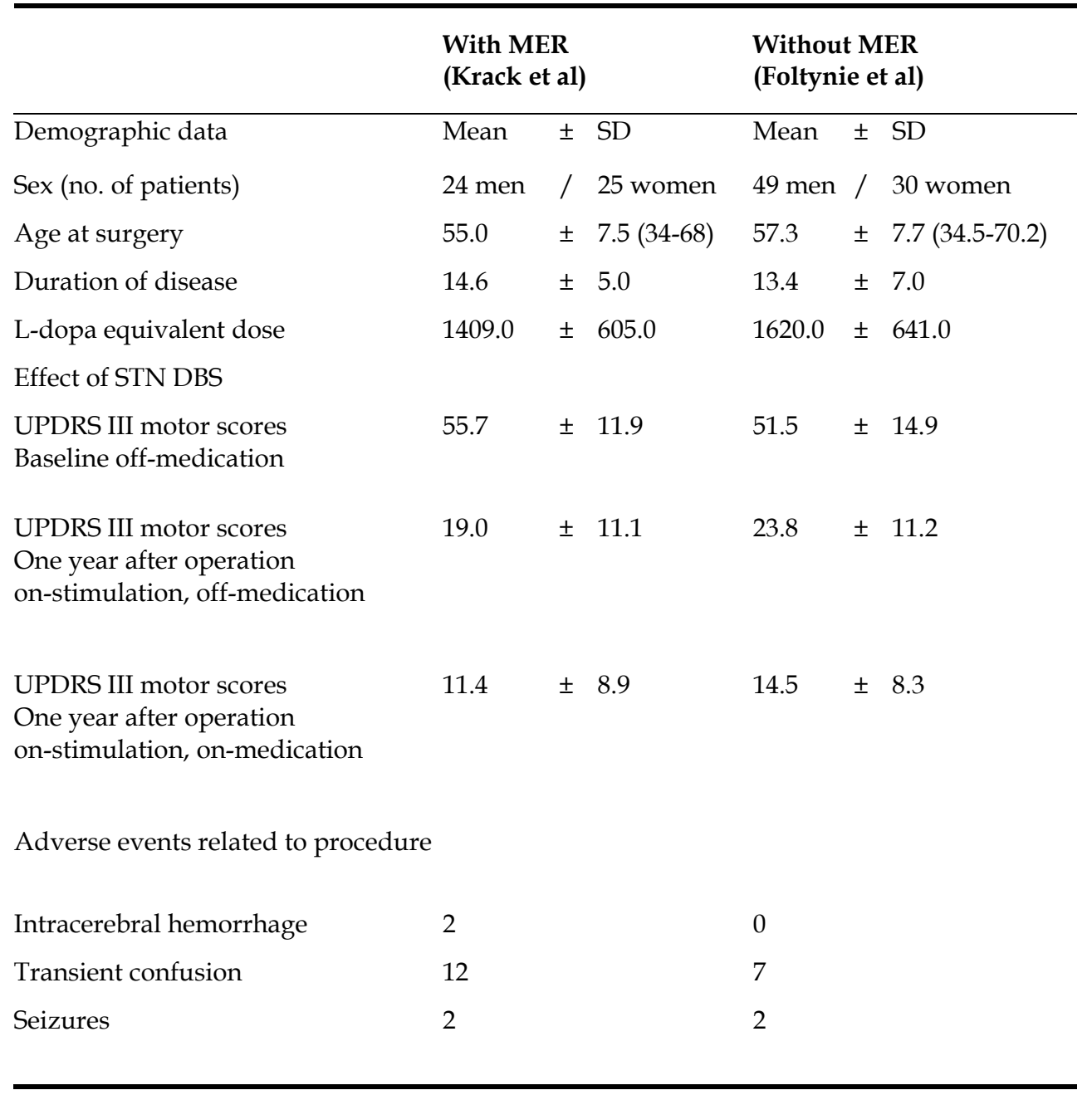

Table 2. Comparison between DBS with and without MER

\section{Anesthetic considerations in DBS: Awake versus general anesthesia}

Traditionally, DBS is an awake surgical procedure in order to allow electrophysiological mapping and stimulation testing to assess motor responses and potential side effects. However, PD patients with obvious "off-medication" symptoms of anxiety, painful dystonia, and respiratory distress may not be good candidates for the lengthy tolerating the surgical procedures while awake [54-57]. In this section, we will report our own experience with general anesthesia during DBS surgery with MER and compare it with data from awake procedures (see Table 3). 


\begin{tabular}{ll}
\hline Operation procedures: & Awake DBS \\
\hline Patient's condition & $\begin{array}{l}\text { communicative and } \\
\text { cooperative; Can tolerate } \\
\text { severe off-symptoms }\end{array}$
\end{tabular}

General Anesthetic DBS

Anxious; Cannot tolerate severe off-symptoms, such as: pain, dystonia and/or respiratory difficulties

Anesthetic agents

Sedative agents

MER signals

Passive movement-related MER signals

Test stimulation

Motor outcome

Surgical complication

Stimulation side effect

Risk period
None

propofol / remifentanil (intermittent use, e.g. during trephination)

Yes

Yes

Yes

Good

Comparable

Lower

During surgery
Desflurane (Patient intubated under regular induction and muscle relaxant, keep Mac around 0.8 1.0) [54]

None

Yes

Yes

No

Good

Comparable

May be higher

Induction and extubation

Patient monitoring by anesthesiologist Yes

Yes

Mac: minimum alveolar concentration

Table 3. Comparison between awake DBS and general anesthetic DBS procedures

\section{Awake DBS procedures}

Most DBS centers prefer that their PD patients receive electrode implantation procedures in an awake state in order to retrieve sound electrophysiological signals from MER and to perform test stimulation. Time is crucial for a patient to tolerate the procedure while awake. Patel et al tried an MRI direct-targeting method with macro-stimulation alone. They conclude that without MER the procedure is more efficient and safe but still has a good outcome [58-59]. In the awake state, macro-stimulation is beneficial because it excludes the side effect from electrode stimulation [59]. Sedative agents are inevitable during awake procedures, especially during trephination. Propofol is popular during DBS procedures as a brief general anesthetic agent, but it may require full-time surveillance of the patient's 
airway and vital signs by an anesthesiologist. The function of the patient's airway can be a severe problem in an advanced PD patient's "off" state.

MER has been shown to perform properly and without affecting the surgical outcome only when remifentanil was completely stopped and the dose of propofol was carefully monitored [52, 58, 60-61]. Duque et al reported a case with these same anesthetic agents using Bispectral Analysis of the Electroencephalogram (BIS) to monitor cortical activity in order to titrate the hypnotics, which may interfere with MER procedures. While this technique may be useful, it is not convenient [62].

\section{General anesthetic DBS procedures}

A detailed MER mapping within the STN may lead to an optimal placement of DBS electrodes, but the drawbacks are the length of the procedure and that the patient must be kept awake during the procedure. Some patients with severe "off-medication" PD symptoms, such as major anxiety, poorly tolerated off-medication dystonia, or respiratory difficulties may refuse DBS or may be poor candidates for DBS in an awake state $[55,57]$. STN-DBS during a state of general anesthesia may be another choice for those patients with advanced PD for whom symptoms are difficult to control with medication only.

In patients with advanced PD who undergo STN-DBS while awake, test stimulation after the permanent electrode is implanted is helpful to confirm the electrode position. The test stimulation verifies the maximal clinical effects intraoperatively as well as the side effects of low voltage in the case that the electrode position was sub-optimal. Test stimulation in patients receiving a general anesthetic is controversial. Hertel et al. performed test stimulation to verify possible capsular effects when using low-voltage electrode stimulation, and the voltage causing the capsular effects may be incorrectly estimated if the excitability of the capsule has been decreased by general anesthesia. In our study, we did not perform test stimulation, but no patient suffered post-operative capsular effects because our selection criteria for the trajectory of electrode implantation chose the most appropriate track [54].

The knowledge of STN topography is crucial in general anesthesia DBS surgery; therefore, MER must be used as it is the only intra-operative tool to identify the STN, map its boundaries, and map its sensorimotor component through the detection of movementrelated neuronal firing [61, 63-65].

\section{The role of anesthesiologist in DBS surgery}

Most anesthesiologists are treating intubated patients under general anesthesia and in awake procedures like DBS, it can be challenging to ensure neuronal firing on the one hand and monitor patient safety the other. Avoiding medications that may interfere with MER can negatively affect patient safety, especially when the patient is agitated by a prolonged DBS procedure. However, it also is difficult to maintain a secure airway if the patient is too deeply unconscious [66-67]. In hypertensive patients, the alpha-2 agonist dexmedetomidine has been suggested as an effective sedative agent that may provide the patient comfort and good blood-pressure control and yet still allow satisfactory MER mapping by the neurophysiologist [67]. Complications may still occur during awake DBS procedures. Deoganokar reported a case of venous air embolism in an elderly PD patient with a myocardial infarction [68]. Glossop and Dobbs also report two cases of coronary artery vasospasm during electrode implantation. Though these patients recovered, the authors suggest full monitoring by an anesthesiologist throughout the surgical procedures [69]. 


\section{The effect of the anesthetic agent desflurane}

Desflurane (2,2,2-trifluoro-1-fluoroethyl-difluoromethyl ether) is a highly fluorinated methylethyl ether used for maintenance of a general anesthetic. It has the most rapid onset and offset of all of the volatile anesthetic drugs used for general anesthesia because of its low solubility in blood. It also is popular in neurosurgery because it can allow early extubation and facilitate early neurological evaluation [70-71]. MER also can be performed well at an anesthetic level of 0.8 \pm 0.2 minimum alveolar concentration (MAC) [54].

\section{Conclusion}

The subthalamic nucleus plays an important role in the functional control of motor activity in the indirect dopaminergic pathway of the basal ganglia. Twenty years after the first introduction of DBS to treat PD, it remains as an important alternative treatment to l-dopa, especially in the patient with motor fluctuation and obvious 1-dopa related complication. Centers performing DBS may have different protocol according to their experiences and facilities. Controversial points exist inevitably, however, through proper patient selections, cooperation between multidisciplinary teams, and refine surgical techniques we can ensure a good outcome for DBS candidate.

\section{Acknowledgment}

This work was supported by Master Cheng Yen, President of the Tzu-Chi Foundation, and Tzu-Chi General Hospital grant TCSP 0104.

\section{References}

[1] Langston J, Widner H, Goetz C, Brooks D, Fahn S, Freeman T, Watts R. Core assessment program for intracerebral transplantations (CAPIT). Mov Disord 1992;7(1):2-13.

[2] Defer G, Widner H, Marie R, Remy P, Levivier M. Core assessment program for surgical interventional therapies in Parkinson's disease (CAPSIT-PD). Mov Disord 1999;14(4):572-84.

[3] Moro E, Allert N, Eleopra R, Houeto J, Phan T, Stoevelaar H. A decision tool to support appropriate referral for deep brain stimulation in Parkinson's disease. J Neurol 2009;256(1):83-8.

[4] Yoshida F, Miyagi Y, Kishimoto J, Morioka T, Murakami N, Hashiguchi K, Samura K, Sakae N, Yamasaki R, Kawaguchi M, Sasaki T. Subthalamic nucleus stimulation does not cause deterioration of preexisting hallucinations in Parkinson's disease patients. Stereotact Funct Neurosurg 2009;87(1):45-9.

[5] Okun MS, Fernandez HH, Rodriguez RL, Foote KD. Identifying candidates for deep brain stimulation in Parkinson's disease: the role of the primary care physician. Geriatrics 2007;62(5):18-24.

[6] Okun MS, Fernandez HH, Pedraza O, Misra M, Lyons KE, Pahwa R, Tarsy D, Scollins L, Corapi K, Friehs GM, Grace J, Romrell J, Foote KD. Development and initial validation of a screening tool for Parkinson disease surgical candidates. Neurology 2004;63(1):161-3.

[7] Amick M, Grace J. Deep brain stimulation surgery for Parkinson's disease: the role of neuropsychological assessment. Med Health R I 2006;89(4):130-3. 
[8] Chang V, Chou K. Deep brain stimulation for Parkinson's disease: patient selection and motor outcomes. Med Health R I 2006;89(4):142-4.

[9] Lang AE, Widner H. Deep brain stimulation for Parkinson's disease: Patient selection and evaluation. Movement Disorders 2002;17(S3):S94-S101.

[10] Bronstein JM, Tagliati M, Alterman RL, Lozano AM, Volkmann J, Stefani A, Horak FB, Okun MS, Foote KD, Krack P, Pahwa R, Henderson JM, Hariz MI, Bakay RA, Rezai A, Marks WJ, Jr, Moro E, Vitek JL, Weaver FM, Gross RE, DeLong MR. Deep Brain Stimulation for Parkinson Disease: An Expert Consensus and Review of Key Issues. Arch Neurol 2010:archneurol.2010.260.

[11] Williams DR, Warren JD, Lees AJ. Using the presence of visual hallucinations to differentiate Parkinson's disease from atypical parkinsonism. Journal of Neurology, Neurosurgery \& Psychiatry 2008;79(6):652-5.

[12] Kollensperger M, Geser F, Seppi K, Stampfer-Kountche... M, Sawires M, Scherfler C, Boesch S, Mueller J, Koukouni V, Quinn N, Pellecchia M, Barone P, Schimke N, Dodel R, Oertel W, Dupont E, Ostergaard K, Daniels C, Deuschl G, Gurevich T, Giladi N, Coelho M, Sampaio C, Nilsson C, Widner H, Sorbo F, Albanese A, Cardozo A, Tolosa E, Abele M, Klockgether T, Kamm C, Gasser T, Djaldetti R, Colosimo C, Meco G, Schrag A, Poewe W, Wenning G. Red flags for multiple system atrophy. Mov Disord 2008;23(8):1093-9.

[13] Reichmann H. Clinical criteria for the diagnosis of Parkinson's disease. Neurodegener Dis 2010;7(5):284-90.

[14] Zhao Y, Wee H, Chan Y, Seah S, Au W, Lau P, Pica E, Li S, Luo N, Tan L. Progression of Parkinson's disease as evaluated by Hoehn and Yahr stage transition times. Mov Disord 2010;25(6):702-8.

[15] Goetz C, Poewe W, Rascol O, Sampaio C, Stebbins G, Counsell C, Giladi N, Holloway R, Moore C, Wenning G, Yahr M, Seidl L. Movement Disorder Society Task Force report on the Hoehn and Yahr staging scale: status and recommendations. Mov Disord 2004;19(9):1020-8.

[16] The Unified Parkinson's Disease Rating Scale (UPDRS): status and recommendations. Mov Disord 2003;18(7):738-50.

[17] Goetz C, Fahn S, Martinez-Martin P, Poewe W, Sampaio C, Stebbins G, Stern M, Tilley B, Dodel R, Dubois B, Holloway R, Jankovic J, Kulisevsky J, Lang A, Lees A, Leurgans S, LeWitt P, Nyenhuis D, Olanow C, Rascol O, Schrag A, Teresi J, Van Hilten J, LaPelle N. Movement Disorder Society-sponsored revision of the Unified Parkinson's Disease Rating Scale (MDS-UPDRS): Process, format, and clinimetric testing plan. Mov Disord 2007;22(1):41-7.

[18] Tsai S, Lin S, Chou Y, Pan Y, Hung H, Li C, Lin S, Chen S. Prognostic factors of subthalamic stimulation in Parkinson's disease: a comparative study between shortand long-term effects. Stereotact Funct Neurosurg 2009;87(4):241-8.

[19] Romito L, Contarino M, Vanacore N, Bentivoglio A, Scerrati M, Albanese A. Replacement of dopaminergic medication with subthalamic nucleus stimulation in Parkinson's disease: long-term observation. Mov Disord 2009;24(4):557-63.

[20] Ory-Magne F, Brefel-Courbon C, Simonetta-Moreau M, Fabre N, Lotterie J, Chaynes P, Berry I, Lazorthes Y, Rascol O. Does ageing influence deep brain stimulation outcomes in Parkinson's disease? Mov Disord 2007;22(10):1457-63. 
[21] Derost P-P, Ouchchane L, Morand D, Ulla M, Llorca P-M, Barget M, Debilly B, Lemaire J-J, Durif F. Is STN-DBS appropriate to treat severe Parkinson disease in an elderly population? Neurology 2007;68(17):1345-55.

[22] Vesper J, Haak S, Ostertag C, Nikkhah G. Subthalamic nucleus deep brain stimulation in elderly patients--analysis of outcome and complications. BMC Neurol 2007;7:7.

[23] Ferrara J, Diamond A, Hunter C, Davidson A, Almaguer M, Jankovic J. Impact of STNDBS on life and health satisfaction in patients with Parkinson's disease. Journal of Neurology, Neurosurgery \& Psychiatry 2010;81(3):315-9.

[24] York MK, Dulay M, Macias A, Levin HS, Grossman R, Simpson R, Jankovic J. Cognitive declines following bilateral subthalamic nucleus deep brain stimulation for the treatment of Parkinson's disease. Journal of Neurology, Neurosurgery \& Psychiatry 2008;79(7):789-95.

[25] Houeto JL, Bejjani PB, Damier P, Staedler C, Bonnet AM, Pidoux B, Dormont D, Cornu $\mathrm{P}$, Agid Y. Failure of long-term pallidal stimulation corrected by subthalamic stimulation in PD. Neurology 2000;55(5):728-30.

[26] Rodriguez-Oroz MC, Obeso JA, Lang AE, Houeto J-L, Pollak P, Rehncrona S, Kulisevsky J, Albanese A, Volkmann J, Hariz MI, Quinn NP, Speelman JD, Guridi J, Zamarbide I, Gironell A, Molet J, Pascual-Sedano B, Pidoux B, Bonnet AM, Agid Y, Xie J, Benabid A-L, Lozano AM, Saint-Cyr J, Romito L, Contarino MF, Scerrati M, Fraix V, Van Blercom N. Bilateral deep brain stimulation in Parkinson's disease: a multicentre study with 4 years follow-up. Brain 2005;128(10):2240-9.

[27] Anderson VC, Burchiel KJ, Hogarth P, Favre J, Hammerstad JP. Pallidal vs Subthalamic Nucleus Deep Brain Stimulation in Parkinson Disease. Arch Neurol 2005;62(4):55460.

[28] Moro E, Lozano A, Pollak P, Agid Y, Rehncrona S, Volkmann J, Kulisevsky J, Obeso J, Albanese A, Hariz M, Quinn N, Speelman J, Benabid A, Fraix V, Mendes A, Welter M, Houeto J, Cornu P, Dormont D, Tornqvist A, Ekberg R, Schnitzler A, Timmermann L, Wojtecki L, Gironell A, Rodriguez-Oroz M, Guridi J, Bentivoglio A, Contarino M, Romito L, Scerrati M, Janssens M, Lang A. Long-term results of a multicenter study on subthalamic and pallidal stimulation in Parkinson's disease. Mov Disord 2010;25(5):578-86.

[29] Follett K, Weaver F, Stern M, Hur K, Harris C, Luo P, Marks W, Rothlind J, Sagher O, Moy C, Pahwa R, Burchiel K, Hogarth P, Lai E, Duda J, Holloway K, Samii A, Horn S, Bronstein J, Stoner G, Starr P, Simpson R, Baltuch G, De Salles A, Huang G, Reda D. Pallidal versus subthalamic deep-brain stimulation for Parkinson's disease. $\mathrm{N}$ Engl J Med 2010;362(22):2077-91.

[30] Volkmann J, Allert N, Voges J, Sturm V, Schnitzler A, Freund H. Long-term results of bilateral pallidal stimulation in Parkinson's disease. Ann Neurol 2004;55(6):871-5.

[31] Schupbach M, Gargiulo M, Welter ML, Mallet L, Behar C, Houeto JL, Maltete D, Mesnage V, Agid Y. Neurosurgery in Parkinson disease: a distressed mind in a repaired body? Neurology 2006;66(12):1811-6.

[32] Voon V, Fernagut P, Wickens J, Baunez C, Rodriguez M, Pavon N, Juncos J, Obeso J, Bezard E. Chronic dopaminergic stimulation in Parkinson's disease: from dyskinesias to impulse control disorders. Lancet Neurol 2009;8(12):1140-9.

[33] Voon V, Krack P, Lang AE, Lozano AM, Dujardin K, Schüpbach M, D'Ambrosia J, Thobois S, Tamma F, Herzog J, Speelman JD, Samanta J, Kubu C, Rossignol H, 
Poon Y-Y, Saint-Cyr JA, Ardouin C, Moro E. A multicentre study on suicide outcomes following subthalamic stimulation for Parkinson's disease. Brain 2008;131(10):2720-8.

[34] Deuschl G, Schade-Brittinger C, Krack P, Volkmann J, Schafer H, Botzel K, Daniels C, Deutschlander A, Dillmann U, Eisner W, Gruber D, Hamel W, Herzog J, Hilker R, Klebe S, Kloss M, Koy J, Krause M, Kupsch A, Lorenz D, Lorenzl S, Mehdorn H, Moringlane J, Oertel W, Pinsker M, Reichmann H, Reuss A, Schneider G, Schnitzler A, Steude U, Sturm V, Timmermann L, Tronnier V, Trottenberg T, Wojtecki L, Wolf E, Poewe W, Voges J. A randomized trial of deep-brain stimulation for Parkinson's disease. N Engl J Med 2006;355(9):896-908.

[35] Bejjani B, Arnulf I, Demeret S, Damier P, Bonnet A, Houeto J, Agid Y. Levodopainduced dyskinesias in Parkinson's disease: is sensitization reversible? Ann Neurol 2000;47(5):655-8.

[36] Nutt JG, Rufener SL, Carter JH, Anderson VC, Pahwa R, Hammerstad JP, Burchiel KJ. Interactions between deep brain stimulation and levodopa in Parkinson's disease. Neurology 2001;57(10):1835-42.

[37] Bejjani B, Damier P, Arnulf I, Bonnet AM, Vidailhet M, Dormont D, Pidoux B, Cornu P, Marsault C, Agid Y. Pallidal stimulation for Parkinson's disease. Two targets? Neurology 1997;49(6):1564-9.

[38] Volkmann J, Allert N, Voges J, Weiss PH, Freund H-J, Sturm V. Safety and efficacy of pallidal or subthalamic nucleus stimulation in advanced PD. Neurology 2001;56(4):548-51.

[39] Hamani C, Saint-Cyr JA, Fraser J, Kaplitt M, Lozano AM. The subthalamic nucleus in the context of movement disorders. Brain 2004;127(1):4-20.

[40] Breit S, LeBas J, Koudsie A, Schulz J, Benazzouz A, Pollak P, Benabid A. Pretargeting for the implantation of stimulation electrodes into the subthalamic nucleus: a comparative study of magnetic resonance imaging and ventriculography. Neurosurgery 2006;58(1 Suppl):ONS83-95.

[41] Cuny E, Guehl D, Burbaud P, Gross C, Dousset V, Rougier A. Lack of agreement between direct magnetic resonance imaging and statistical determination of a subthalamic target: the role of electrophysiological guidance. J Neurosurg 2002;97(3):591-7.

[42] Chen S, Lee C, Lin S, Hsin Y, Lee T, Yen P, Chou Y, Lee C, Annie Hsieh W, Su C, Lin S. Microelectrode recording can be a good adjunct in magnetic resonance imagedirected subthalamic nucleus deep brain stimulation for parkinsonism. Surg Neurol 2006;65(3):253-60; discussion 60-1.

[43] Andrade-Souza Y, Schwalb J, Hamani C, Eltahawy H, Hoque T, Saint-Cyr J, Lozano A. Comparison of three methods of targeting the subthalamic nucleus for chronic stimulation in Parkinson's disease. Neurosurgery 2005;56(2 Suppl):360-8; discussion -8 .

[44] Aziz TZ, Nandi D, Parkin S, Liu X, Giladi N, Bain P, Gregory RG, Joint C, Scott RB, Stein JF. Targeting the subthalamic nucleus. Stereotact Funct Neurosurg 2001;77(14):87-90.

[45] Hariz M, Krack P, Melvill R, Jorgensen J, Hamel W, Hirabayashi H, Lenders M, Wesslen N, Tengvar M, Yousry T. A quick and universal method for stereotactic 
visualization of the subthalamic nucleus before and after implantation of deep brain stimulation electrodes. Stereotact Funct Neurosurg 2003;80(1-4):96-101.

[46] Vitek JL, Bakay RA, Hashimoto T, Kaneoke Y, Mewes K, Zhang JY, Rye D, Starr P, Baron M, Turner R, DeLong MR. Microelectrode-guided pallidotomy: technical approach and its application in medically intractable Parkinson's disease. J Neurosurg 1998;88(6):1027-43.

[47] Starr PA, Vitek JL, Bakay RA. Deep brain stimulation for movement disorders. Neurosurg Clin N Am 1998;9(2):381-402.

[48] Patel NK, Plaha P, Gill SS. Magnetic resonance imaging-directed method for functional neurosurgery using implantable guide tubes. Neurosurgery 2007;61(5 Suppl 2):35865; discussion 65-6.

[49] Foltynie T, Zrinzo L, Martinez-Torres I, Tripoliti E, Petersen E, Holl E, Aviles-Olmos I, Jahanshahi M, Hariz M, Limousin P. MRI-guided STN DBS in Parkinson's disease without microelectrode recording: efficacy and safety. J Neurol Neurosurg Psychiatry 2010.

[50] Krack P, Batir A, Van Blercom N, Chabardes S, Fraix V, Ardouin C, Koudsie A, Limousin PD, Benazzouz A, LeBas JF, Benabid AL, Pollak P. Five-year follow-up of bilateral stimulation of the subthalamic nucleus in advanced Parkinson's disease. $\mathrm{N}$ Engl J Med 2003;349(20):1925-34.

[51] Ben-Haim S, Asaad WF, Gale JT, Eskandar EN. Risk factors for hemorrhage during microelectrode-guided deep brain stimulation and the introduction of an improved microelectrode design. Neurosurgery 2009;64(4):754-62; discussion 62-3.

[52] Binder DK, Rau GM, Starr PA. Risk factors for hemorrhage during microelectrodeguided deep brain stimulator implantation for movement disorders. Neurosurgery 2005;56(4):722-32; discussion -32.

[53] Kleiner-Fisman G, Herzog J, Fisman DN, Tamma F, Lyons KE, Pahwa R, Lang AE, Deuschl G. Subthalamic nucleus deep brain stimulation: summary and metaanalysis of outcomes. Mov Disord 2006;21 Suppl 14:S290-304.

[54] Lin S, Chen T, Lin S, Shyr M, Chou Y, Hsieh W, Tsai S, Chen S. Subthalamic deep brain stimulation after anesthetic inhalation in Parkinson disease: a preliminary study. J Neurosurg 2008;109(2):238-44.

[55] Hertel F, Zuchner M, Weimar I, Gemmar P, Noll B, Bettag M, Decker C. Implantation of electrodes for deep brain stimulation of the subthalamic nucleus in advanced Parkinson's disease with the aid of intraoperative microrecording under general anesthesia. Neurosurgery 2006;59(5):E1138; discussion E.

[56] Yamada K, Goto S, Kuratsu J, Matsuzaki K, Tamura T, Nagahiro S, Murase N, Shimazu $\mathrm{H}$, Kaji R. Stereotactic surgery for subthalamic nucleus stimulation under general anesthesia: a retrospective evaluation of Japanese patients with Parkinson's disease. Parkinsonism Relat Disord 2007;13(2):101-7.

[57] Maltete D, Navarro S, Welter M-L, Roche S, Bonnet A-M, Houeto J-L, Mesnage V, Pidoux B, Dormont D, Cornu P, Agid Y. Subthalamic Stimulation in Parkinson Disease: With or Without Anesthesia? Arch Neurol 2004;61(3):390-2.

[58] Patel NK, Plaha P, O'Sullivan K, McCarter R, Heywood P, Gill SS. MRI directed bilateral stimulation of the subthalamic nucleus in patients with Parkinson's disease. Journal of Neurology, Neurosurgery \& Psychiatry 2003;74(12):1631-7. 
[59] Tabbal S, Revilla F, Mink J, Schneider-Gibson P, Wernle A, de Erausquin G, Perlmutter J, Rich K, Dowling J. Safety and efficacy of subthalamic nucleus deep brain stimulation performed with limited intraoperative mapping for treatment of Parkinson's disease. Neurosurgery 2007;61(3 Suppl):119-27; discussion 27-9.

[60] Amirnovin R, Williams Z, Cosgrove G, Eskandar E. Experience with microelectrode guided subthalamic nucleus deep brain stimulation. Neurosurgery 2006;58(1 Suppl):ONS96-102; discussion ONS96-.

[61] Hariz M, Blomstedt P, Limousin P. The myth of microelectrode recording in ensuring a precise location of the DBS electrode within the sensorimotor part of the subthalamic nucleus. Mov Disord 2004;19(7):863-4.

[62] Duque P, Mateo O, Ruiz F, de Viloria J, Contreras A, Grandas F. Intraoperative microrecording under general anaesthesia with bispectral analysis monitoring in a case of deep brain stimulation surgery for Parkinson's disease. Eur J Neurol 2008;15(8):e76-7.

[63] Romanelli P, Heit G, Hill B, Kraus A, Hastie T, Bronte-Stewart H. Microelectrode recording revealing a somatotopic body map in the subthalamic nucleus in humans with Parkinson disease. J Neurosurg 2004;100(4):611-8.

[64] Mandat T, Hurwitz T, Honey C. Hypomania as an adverse effect of subthalamic nucleus stimulation: report of two cases. Acta Neurochir (Wien) 2006;148(8):895-7; discussion 8.

[65] Tsai S, Lin S, Lin S, Chen J, Lee C, Chen S. Neuropsychological effects after chronic subthalamic stimulation and the topography of the nucleus in Parkinson's disease. Neurosurgery 2007;61(5):E1024-9; discussion E9-30.

[66] Kalenka A, Schwarz A. Anaesthesia and Parkinson's disease: how to manage with new therapies? Curr Opin Anesthesiol 2009;22(3):419-24.

[67] Rozet I, Muangman S, Vavilala MS, Lee LA, Souter MJ, Domino KJ, Slimp JC, Goodkin R, Lam AM. Clinical Experience with Dexmedetomidine for Implantation of Deep Brain Stimulators in Parkinson's Disease. Anesthesia \& Analgesia 2006;103(5):12248.

[68] Deogaonkar A, Avitsian R, Henderson J, Schubert A. Venous air embolism during deep brain stimulation surgery in an awake supine patient. Stereotact Funct Neurosurg 2005;83(1):32-5.

[69] Glossop A, Dobbs P. Coronary artery vasospasm during awake deep brain stimulation surgery. British Journal of Anaesthesia 2008;101(2):222-4.

[70] Magni G, Rosa IL, Melillo G, Savio A, Rosa G. A Comparison Between Sevoflurane and Desflurane Anesthesia in Patients Undergoing Craniotomy for Supratentorial Intracranial Surgery. Anesthesia \& Analgesia 2009;109(2):567-71.

[71] Bilotta F, Doronzio A, Cuzzone V, Caramia R, Rosa G. Early postoperative cognitive recovery and gas exchange patterns after balanced anesthesia with sevoflurane or desflurane in overweight and obese patients undergoing craniotomy: a prospective randomized trial. J Neurosurg Anesthesiol 2009;21(3):207-13.

[72] Kumar R, Lozano AM, Montgomery E, Lang AE. Pallidotomy and deep brain stimulation of the pallidum and subthalamic nucleus in advanced Parkinson's disease. Mov Disord 1998;13 Suppl 1:73-82. 


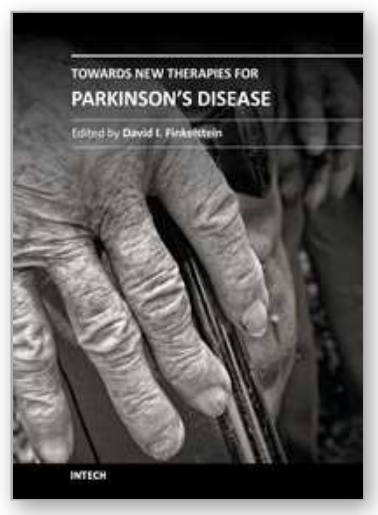

\section{Towards New Therapies for Parkinson's Disease}

Edited by Prof. David Finkelstein

ISBN 978-953-307-463-4

Hard cover, 396 pages

Publisher InTech

Published online 02, November, 2011

Published in print edition November, 2011

Parkinson's disease (PD) is characterised clinically by various non-motor and progressive motor symptoms, pathologically by loss of dopamine producing cells and intraneuronal cytoplasmic inclusions composed primarily of ?-synuclein. By the time a patient first presents with symptoms of Parkinson's disease at the clinic, a significant proportion of the cells in the substantia nigra have already been destroyed. This degeneration progresses despite the current therapies until the cell loss is so great that the quality of normal life is compromised. The dopamine precursor levodopa is the most valuable drug currently available for the treatment of PD. However for most PD patients, the optimal clinical benefit from levodopa decreases around five to six years of treatment. The aim of the chapters of this book is to work towards an understanding in the mechanisms of degeneration and to develop disease modifying therapies.

\section{How to reference}

In order to correctly reference this scholarly work, feel free to copy and paste the following:

Shin-Yuan Chen, Sheng-Tzung Tsai and Sheng-Huang Lin (2011). Controversial Issues in Deep Brain Stimulation in Parkinson's Disease, Towards New Therapies for Parkinson's Disease, Prof. David Finkelstein (Ed.), ISBN: 978-953-307-463-4, InTech, Available from: http://www.intechopen.com/books/towards-newtherapies-for-parkinson-s-disease/controversial-issues-in-deep-brain-stimulation-in-parkinson-s-disease

\section{INTECH}

open science | open minds

\author{
InTech Europe \\ University Campus STeP Ri \\ Slavka Krautzeka 83/A \\ 51000 Rijeka, Croatia \\ Phone: +385 (51) 770447 \\ Fax: +385 (51) 686166 \\ www.intechopen.com
}

\author{
InTech China \\ Unit 405, Office Block, Hotel Equatorial Shanghai \\ No.65, Yan An Road (West), Shanghai, 200040, China \\ 中国上海市延安西路65号上海国际贵都大饭店办公楼 405 单元 \\ Phone: +86-21-62489820 \\ Fax: +86-21-62489821
}


(C) 2011 The Author(s). Licensee IntechOpen. This is an open access article distributed under the terms of the Creative Commons Attribution 3.0 License, which permits unrestricted use, distribution, and reproduction in any medium, provided the original work is properly cited. 